\title{
CONSIDERACIONES SOBRE EL SER HUMANO y su singularidad frente a las concepciones antropológicas actuales de carácter tecnocientífico
}

\author{
Luis Miguel Pastor \\ Universidad de Murcia
}

Resumen: Los nuevos avances biotecnológicos están siendo utilizados por ciertos pensadores contemporáneos para propugnar no sólo un mejoramiento del hombre sino la transformación de él en un nuevo ser posthumano. Tal propuesta lleva a volver a reflexionar sobre la singularidad humana y su posible superación. Plantean que esto es posible en cuanto que tal singularidad puede ser suplantada por un nuevo género de seres inteligentes de carácter artificial, pudiendo el hombre primero hibridarse y posteriormente incorporarse a ellos en nuevo género de "vida". En el trabajo sostenemos que este planteamiento parte de una concepción del hombre dualista en el que la corporeidad es un componente que no tiene conexión con la singularidad humana. Asímismo solo considera la dimensión cognitiva humana como esencial de esa singularidad. De esta manera, los discursos transhumanistas-posthumanistas pueden imaginar supuestos seres inteligentes no humanos idénticos a los humanos e incluir a los segundos en ellos para que éstos sean superinteligentes o inmortales. Tal planteamiento es irreal y, como tal, falso. La condición de viviente es esencial en la definición de hombre y permite al ser humano poseer una actividad propia diferente a la que se genera en una máquina. Gracias a esto, la actividad cognoscitiva-apetitiva humana no está circunscrita, sino abierta al medio, el cual se convierte en un mundo que está lleno de significado y sentido. Asímismo, el querer humano aspira a perfeccionar y llevar a plenitud el propio ser del hombre en un comportamiento singular que es el ético. Éste modifica al hombre en cuanto a su bondad y realiza su plenitud en la relación interpersonal a través de un amor de amistad que quiere el bien del otro. En conclusión, estas últimas características del querer humano deben ser consideradas siempre que se plantee la singularidad humana, y ponen de manifiesto de una forma más explícita el abismo que separa al hombre de cualquier inteligencia artificial por muy desarrollada que esta sea.

Palabras claves: Inteligencia artificial, singularidad, transhumanismo- posthumanismo, amor humano, libertad.

Considerations on to want human and its singularity versus current anthropological conceptions of the technoscience.

Abstract: The new biotechnological advances are being used by certain contemporary thinkers to advocate not only an improvement of man but the transformation of him into a new post-human being. Such a proposal leads us to reflect again on human singularity 
and its possible overcoming. They suggest that this is possible in that such a singularity can be supplanted by a new genre of intelligent beings of an artificial nature, and man can first hybridize and subsequently join them in a new genre of "life." In the work we maintain that this approach is based on a conception of dualistic man in which corporeality is a component that has no connection to human singularity. Likewise, it only considers the human cognitive dimension as essential to that singularity. In this way, transhumanist-posthumanist discourses can imagine supposed nonhuman intelligent beings identical to humans and include the latter in them so that they are superintelligent or immortal. Such an approach is unreal and as such false. The living entity condition is essential in the definition of man and allows the human being to possess an activity of his own different from that generated in a machine. Thanks to this, human cognitive-appetitive activity is not circumscribed, but open to the environment, which becomes a world, which is full of meaning and sense. Likewise, the human will aspires to perfect and bring to fullness the very being of man in a singular ethical behaviour. This modifies man in terms of his goodness and leads him to fullness in the interpersonal relationship through a love of friendship that wants the good of the other. In conclusion, these last characteristics of the human will must be considered whenever human singularity and is raised they show in a more explicit way the abyss that separates man from any artificial intelligence, however developed she may be.

Keywords: Artificial Intelligence, singularity, transhumanism-posthumanism, human love, free will.

Recibido: 3 de diciembre de 2019. Aprobado: 15 de diciembre de 2019.

\section{Introducción}

Hace bastantes años, cuando compaginaba mis estudios de biología con filosofía tuve la oportunidad —en la asignatura de antropología filosóficade estudiar las diversas reflexiones que el pensamiento humano ha propuesto a través de la historia para contestar a la pregunta: ¿qué es el hombre? Determinar la esencia humana, "lo que es", parece ser una tarea que vuelve a replantearse en cada generación, quizá porque nuestro conocimiento sobre la mente y el cuerpo humano va creciendo de forma progresiva con el pasar de los años. Este hecho facilita a mí entender, que a 
la luz de ese nuevo conocimiento nos replanteemos de forma continua la idea de lo que es el hombre, en cuanto se nos permite tener cada vez una mejor imagen del ser humano. Por ejemplo, en aquellos años, la etología se había constituido ya en una ciencia y muchos pensadores del siglo XX habían considerado como objeto de estudio analizar las diferencias de comportamiento entre el hombre y los animales, a la búsqueda de encontrar o no una diferencia con ellos. Tal diferencia podría ser esencial o de grado, pero era un nuevo modo de indagar sobre la naturaleza humana, partiendo de los muchos datos que durante décadas se habían obtenido en la biología del comportamiento, como también se estaba haciendo con los conocimientos de la paleoantropología o la etnografía. Autores como Jakob Johann von Uexküll, Arnold Gehlen, Max Scheler, en su libro "El puesto del hombre en el cosmos (1928)", o Adolf Portmann, analizan y hacen hincapié en alguna característica o propiedad del ser humano para afirmar su singularidad en el universo: el lenguaje, la cultura, la libertad, su poder de dotar de sentido el mundo, la falta de una base instintiva rígida, etc. Es evidente, que toda esta pléyade de autores con sus aportaciones ha fortalecido y enriquecido la disciplina de la antropología filosófica, pero también han supuesto una cierta fragmentación sobre lo que pensamos que somos, es decir, sobre el propio concepto o idea que el hombre tiene de sí mismo.

\section{La singularidad del hombre en la actual época postmoderna}

En este comienzo del siglo XXI el tema sigue lógicamente de actualidad —nunca dejará de serlo-, pero con la matización de que ahora el hombre es comparado especialmente con las máquinas inteligentes, llegándose hasta plantear si éstas son humanas, si tienen dignidad y como tales derechos. En esta línea hasta algunos consideran que los hombres y las máquinas están llamados a entenderse. Es más, si en el siglo XX el debate sobre la diferencia hombre-animal, buscaba determinar: a) Si hay algo específico en el hombre que no exista en los animales y b) si tal cualidad podría ser o no 
reducida a términos materiales o evolutivos, en la actualidad, en consonancia con el pensamiento reductivo que caracteriza la postmodernidad, el debate intelectual sobre esta materia tiene otro enfoque. Hoy en día no se trata de afirmar que la singularidad del hombre ha sido abolida, en cuanto que es un simple animal evolucionado, sino más bien hacerlo de una forma oblicua. Se trata de plantear de forma hipotética un sencillo silogismo para negar tal singularidad. Así, se afirma que si fuéramos capaces de hacer máquinas que cada vez se asemejen o se parezcan a los humanos y realicen las funciones que hemos considerado siempre las más nobles o propias del hombre y no fuéramos capaces ni de darnos cuenta de ello, esto significaría que nuestra realidad humana sería similar a las de la maquinas inteligentes. De esta forma, los robots humanoides o androides, serían otro tipo de seres inteligentes como nosotros y, como ellos, nosotros seríamos reductibles a pura materia. No existiría en consecuencia una singularidad de carácter cualitativo que nos constituyera en una especie distinta a ellos, pues hasta existirían seres inteligentes que nos superarían en muchas de las funciones que hasta ahora hemos considerado exclusivamente humanas. En el fondo estamos ante el uso de una analogía. Si el hombre A no lo podemos diferenciar del humanoide $\mathrm{B}$ es que $\mathrm{B}$ es poseedor de lo especifíco o esencial de $\mathrm{A}$. Ahora bien, podríamos argumentar que, aunque nuestra percepción nos confundiera y pensáramos que estamos ante un hombre, nos cabría la posibilidad de mostrar que este humanoide no es un animal y por consiguiente no es del género homo. De esta forma, el humanoide no sería un animal racional y, por consiguiente, no un hombre. Pero si cambiamos la definición del hombre como animal racional, en cuanto la consideramos inadecuada a la realidad humana, la argumentación puede ser elaborada de otra forma. Si los seres del universo son clasificados como no inteligentes e inteligentes, entonces el hombre sería un "inteligente animal" frente a una "inteligente maquina”. Lo específico humano - lo cualitativo - pasaría a ser el género y la especie sería la mera constitución material. Si se hace esto la argumentación ahora deja con mayor semejanza al hombre y a la maquina en cuanto que los dos son inteligencias. Es cierto que nunca una máquina será un 
hombre, en cuanto este es vivo, pero la diferencia entre ambos será ahora una cuestión meramente material. De esta manera, la cuestión actual de la singularidad humana queda reducida a que ésta es un producto de la propia acción del hombre. Si antes — pensaban algunos- ésta podría ser derivada y explicada desde un grado de organización de la materia viva concreta, ahora se la hace derivar de la capacidad tecnológica del hombre, que genera una maquina inteligente. Al final, en ambas formas de razonar late una concepción del hombre que lo considera como un ser estrictamente material y, en ambas, se intenta mostrar cómo desde la materia inanimada o desde la inerte podemos generarlo, negando por consiguiente la existencia de cualquier otro principio de carácter no material en la esencia humana. Eso sí, esta visión antropológica se basa en concebir que en el hombre hay dos realidades yuxtapuestas (dualismo) una corporal y otra mental. Entre ambas hay una relación instrumental, por la cual la corporal se subordina a la mental. Modificar la primera a través de cambios biotecnológicos es algo prioritario para hacer avanzar a la mental. Es más, el sacrificio de esa corporalidad y su total sustitución, tarde o temprano, por un hardware físico se justifica en aras de conseguir un hombre superinteligente, feliz e inmortal.

\section{El posthumano generado a la medida de los deseos del humano}

De esta manera, este planteamiento especulativo pretende llegar a un plano práctico y técnico. Disolver la singularidad del hombre en sus propias creaciones materiales se proyecta como una oportunidad a los propios deseos del hombre. Como hemos indicado, la mejora del hombre — planteada por el movimiento transhumanista-posthumanista- pasaría por la hibridación de nuestra actual naturaleza con elementos de estos seres inteligentes para eliminar nuestras discapacidades y limitaciones biológicas, ampliando las capacidades actuales o adquiriendo nuevas de forma artificial o sintética. Mediante un proceso evolutivo dirigido por el hombre y citando a un autor "inducido por las tecnologías emergentes, el transhumano y posteriormente 
el posthumano"1 llegarían a alcanzar "una superinteligencia, una superlongevidad y un superbienestar desconocidos por la humanidad hasta el día de hoy"2. En este contexto, la biología humana evolucionaría gracias a la tecnología humana autoconstruyéndose una nueva realidad humana, más que humana, una nueva especie que tendría como hermanos otros seres, conformando un nuevo género: el de los organismos tecnológicos. El hombre como tal devendría o terminaría diluido - y añado salvado- dentro de un nuevo conjunto de seres, tanto artificiales como originariamente naturales, que serían sintientes y presentarían unas cualidades intelectuales superiores a las del hombre actual. El posthumano sería en consecuencia una vida artificial sentiente más, dentro de un conjunto de realidades autónomas, auto-conscientes y capaces de reproducirse ${ }^{3}$. En este nuevo género de seres - no animales - el posthumano al que el hombre evolucionaría, mejoraría en su capacidad de comprender, gestionar e integrar la complejidad; tendría una mayor aptitud para capturar, procesar, almacenar y transmitir información; y finalmente poseería más y mejor capacidad organizativa. Por tanto, la evolución tecnológica superaría la evolución biológica y tendría un mayor potencial de generar formas inteligentes, complejas, autoconscientes, sintientes, más comunicativas y mejor organizadas. Como se ve, este planteamiento pretende llegar a un hombre distinto en el que si fuera necesario la actual corporalidad sería sacrificada, anulada o abolida. Tal supresión tendría una finalidad buena: engendrar una inédita criatura humana superior a la actual.

\section{Algunas consideraciones previas a la crítica}

En todo este relato futurista que he descrito y que en algunos puntos muestra la añoranza de un hombre nuevo, uno siente que detrás del mismo

${ }^{1}$ Albert Cortina Ramos, Transhumanismo y singularidad tecnologica: superinteligencia, superlongevidad y superbienestar. [http://www.fragmenta.cat/ponencia-de-albert-cortina 420424.pdf] p. 2. 12.10.2019.

${ }^{\overline{2}}$ Albert Cortina Ramos, p. 2

${ }^{33}$ Albert Cortina Ramos, p. 8 
subyacen ciertas premisas antropológicas que lo sustentan —alguna ya la he indicado-y que son obviadas en aras de simplificar el mensaje que se pretende comunicar. En consecuencia, esto genera un hipotético hombre futuro que quizá nunca existirá. De forma sencilla, a mi modo de ver, este relato se basa en considerar que lo específicamente humano se reduce a:

a) Considerar el hombre como un ser cuya esencia es la capacidad de resolver problemas lógicos o técnicos; b) que tiene cierta conciencia de sí y c) aunque llegara a ser un ser corporalmente de silicio y de chips —un ser inorgánico e inanimado- podrá presentar ciertas propiedades de los vivientes como son la percepción, los sentimientos y el conocimiento del medio, que en el caso del hombre es del mundo, a través de su entendimiento.

No entro a debatir si es estos seres realmente podrán llegar a tener autoconciencia, entendimiento o sentir, pero sí que planteo algunas preguntas en otras direcciones: ¿Realmente estos seres serían mejores que los humanos? ¿Tendrían todas las capacidades humanas y en grado eminente? ¿No parece que este relato toma como punto de partida — para la génesis del posthumano- un modelo de hombre distorsionado? ¿Hay en este discurso una visión de fondo — no sólo dualista — sino reduccionista en que lo mental solo se identifica con la inteligencia o el pensamiento? ¿No se vertebrará el concepto de posthumano sobre la idea de un ser humano limitado y amputado de su condición de viviente que no sólo conoce sino quiere? ¿Es posible hablar de algo plenamente humano desconectado de su realidad de viviente tal como se plantea en este relato? Por último, ¿no habrá un error antropológico de base en estos poshumanismos que consideran que en el hombre hay un algo que nos hace humanos más que considerar que es el todo, lo que es humano?

\section{Posicionamiento crítico}

Evidentemente el recurso retórico utilizado indica que mi posición es muy crítica respecto a la imagen que nos da el posthumanismo tanto del 
hombre actual como de la realidad que de él se podría generar con la tecnología que ellos pretenden utilizar, especialmente porque:

a) No considera que el ser humano es tal como es, no sólo porque sea racional. La esencia humana no es algo singular sino dual, omitiendo en todo su razonamiento antropológico "que en el concepto "hombre" las notas de "animal" y "racional" no funcionan como otros tantos conceptos, sino como aspectos o momentos de una misma estructura unitaria; se trata solamente y a la vez de aquel animal que es racional o de aquel ser racional que es animal" ${ }^{4}$ Como consecuencia de ello, no se advierte que es esencial al hombre y parte constitutiva de su identidad poseer una materia orgánica y que esté viva. El ser humano existe como viviente y como tal presenta lo específico de él: capacidad de automovimiento. Esta presencia hace que el vivir sea lo propio del ser vivo, no algo que advenga desde el exterior y sea otorgado externamente. Supone una espontaneidad e inmanencia que hacen fácil distinguir entre los seres animados e inanimados. Es más, esta cualidad posibilita la existencia de una cierta posesión de uno mismo y de una interioridad, que es mayor o menor según el grado del vivir que ese ser posea. Además, el viviente presenta una actividad que se origina desde él de forma autónoma para cubrir sus necesidades. El sistema vivo no es por lo tanto un sistema simplemente homeostático que realiza funciones sólo de mantenimiento. Su conocimiento y su apetición están dirigidos también a crecer y desarrollar sus propias potencialidades. Verdaderamente cuesta pensar o imaginar que se pueda afirmar todo esto de un sistema material no vivo aunque éste, mecánicamente, aprenda o posea cierto grado de adaptabilidad al medio. En síntesis y en mi opinión, no es posible seguir considerando

${ }^{4}$ Antonio Millan Puelles, Fundamentos de Filosofía. Madrid, Ediciones Rialp, 7 edición, 1970, p. 94. 
que exista una similitud entre un ser vivo y una máquina o artefacto humano, aunque éste último esté basado en circuitos construidos de forma más sofisticada intentando asemejarse a los de carácter biológico. ${ }^{5}$

b) Junto a esto es necesario considerar que una de las características del hombre es que sus cualidades vitales están formalmente poco prefijadas, de forma que las necesidades a cubrir no son tan concretas. Esto permite un conocimiento y una apetición muy diversificada, no circunscrita, sino abierta al medio, el cual se convierte en un mundo que está lleno de significado y sentido. Siguiendo una comparación clásica: "Eros no es un dios; no tiene la opulencia entitativa; antes bien, como hijo de Penia, es un ente precario, a medias, indigente. Como hijo de Poros, sin embargo, es rico en recursos para perfeccionar y completar su ser. Análogamente, el hombre es un ser precario; pero dispone de una capacidad de perfeccionamiento que remedia, a su modo, esa constitutiva imperfección y en la cual radica su excelencia" ${ }^{6}$. De esta manera, y siguiendo la clásica afirmación de que el obrar sigue al ser, encontramos que la actividad humana es muy singular, no solo en cuanto procede de sí, sino que genera comportamientos que están fuera de las necesidades biológicas relacionadas con la supervivencia. Es más, hasta éstas son modificadas y sufren una variada modalización en su realización individual.

\footnotetext{
${ }^{5}$ En esta línea estaría en mi opinión las siguientes palabras de una entrevista a Luis Echarte" ¿Qué diferencia hay entre los movimientos dirigidos a un objetivo y los que no lo están? Es una perspectiva muy antigua: para comprender nuestra psique deberíamos remontarnos al problema del alma, estudiar qué da vida al cuerpo, para luego entender la inteligencia como un tipo de movimiento vital. Y es que la teleología no está sólo en la raíz de la conducta humana sino también del pensamiento. El reto está en entender en qué manera la teleología es previa a la mente, lo que significa que la realidad, al menos la materia con alma -la materia animada-, posee cierta capacidad para trascenderse o, si se prefiere, cierto grado de interioridad." [http://www. socialtrendsinstitute.org/news/what-differentiates-humans-frommachines] 10.10.2019. Un desarrollo de estas ideas en: Luis Echarte, Teleological markers: Seven lines of hypotheses around Dennett's theory of habits, ScientiaetFides 2(2)2014,135184.

${ }^{6}$ Antonio Millan Puelles, Fundamentos de Filosofía. Madrid, Ediciones Rialp, 7 edición, 1970, p. 35.
} 
Luis Miguel Pastor

c) A la luz de lo indicado no sólo la idea del hombre de la que se parte en el movimiento del trashumanismo-posthumanismo está sesgada por la ausencia del cuerpo como parte constitutiva del hombre, —reducido solo a mente- sino que dentro de ésta existe también un olvido de todo lo que en ella es de carácter apetitivo. Los planteamientos transhumanistas-posthumanistas parten de considerar que lo específicamente humano es solo el pensamiento, o como mucho, éste junto a sensaciones, emociones o sentimientos. Esta perspectiva evidencia, por un lado, el fuerte influjo en este movimiento de la filosofía anglosajona y, por otro, la concepción fragmentada - fruto de esa influencia - que se tiene del hombre, desgajando no sólo la mente del cuerpo sino también separando lo intelectivo de lo apetitivo y reduciendo lo segundo a sensaciones o emociones. Tal concepción de lo que es el hombre, evidentemente, deja poco espacio al amor, al deseo o la intención como realidades que, en una concepción unitaria del hombre, son tan importantes como el razonamiento o el juicio de la razón.

\section{Hacia una propuesta}

Dejando ya aparte el análisis crítico de cómo el transhumanismo-posthumanismo considera la singularidad humana, paso a indicar algunas características humanas propias que considero que son difícilmente asumibles por las máquinas inteligentes. Partiendo de una concepción unitaria del hombre en la que tanto el conocer como el apetecer se requieren entre sí y considerando, como he dicho antes, que la singularidad está en el todo, me centraré brevemente en algunas de las características del apetecer humano dejando fuera las que hacen referencia al plano del conocimiento. No voy a extenderme mucho en ellas ni en indicarlas todas, pero sí que me gustaría que al comentarlas pudiera mostrar la dificultad intrínseca que existe en que los organismos tecnológicos puedan poseerlas.

a) La apetencia humana no sólo surge de una emoción o un sentimiento reflejo o condicionado. Las más íntimas y personales están unidas al pensamiento en cuanto que éste propone fines, razones o bienes para ser 
queridos. Estos responden a necesidades humanas variadas y los fines últimos que presenta la razón están relacionados con la consecución de una vida más lograda. Esta es la actividad racional que denominamos práctica y que se correlaciona con la propia capacidad apetitiva humana, que muestra una apertura y una inclinación no sólo hacia fines concretos, para satisfacer necesidades específicas, sino que apetece, quiere y desea fines para sí mismo como hombre. El querer humano, en su núcleo más profundo aspira a perfeccionar y llevar a plenitud el propio ser del hombre en cuanto que éste requiere ser completado. Esta interacción cognoscitiva-volitiva determina un comportamiento humano singular que es el ético. En éste el hombre elige e intenta —no por fuerzas externas heterónomas— desde sí mismo a alcanzar ciertos fines o bienes y lo que él decide no está predeterminado, sino que se genera cada vez que se realiza una elección "ex novo".

b) Así, los bienes presentados al apetito no lo determinan a él de una forma necesaria. La razón presenta o indica el más conveniente después de una deliberación, pero el apetito puede o no puede aceptarlos. Como resultado de ello el comportamiento que se genera no es automático o estereotipado o irracional. Y no lo es porque, como bien sabemos, previo a él hay una decisión o elección, que supone un hacer algo porque quiero o no quiero o, dicho de forma más coloquial, "porque me da la gana". Esta capacidad de ejecución y de autodeterminación respecto a un bien caracteriza como libre el querer humano, así como desde donde este se origina: la voluntad humana. Después de una simple inclinación de amor hacia un bien y el deseo correspondiente de él, el hombre lo elige o no, da su consentimiento o lo rechaza y, en su caso, intenta la acción que quiere, siendo capaz de justificar porque lo hace, todo lo cual supone que el comportamiento sea responsable. Por último, es muy probable que en muchas ocasiones el hombre, para llevar adelante su acción, hasta haya tenido que superar también dificultades internas para realizarla, lo cual resalta aun más si cabe que la acción procede o se origina desde la misma voluntad. Es decir, como indicábamos antes, esta actividad voluntaria es de carácter autodeterminativo, es un querer o no querer algo concreto que le ha sido presentado por la 
razón como bien. De esta forma, el comportamiento humano muestra su carácter propio, en cuanto que el hombre realiza en su existencia una libre afirmación de su ser y no simplemente una necesaria explicitación del mismo. Sin llegar a formulaciones extremas donde la esencia humana es configurada por la voluntad libre, y que podrían tener como precedente la idea tan conocida de Giovanni Pico della Mirandola, según la cual la voluntad puede obrar "para que tú mismo, como modelador y escultor de ti mismo, más a tu gusto y honra, te forjes la forma que prefieras para ti" ${ }^{7}$, es evidente que el ser humano se dirige a su fin por sí mismo tal como expresan tantos autores clásicos como el mismo Tomas de Aquino: "por tanto, es propio de la naturaleza racional tender a un fin moviéndose o dirigiéndose a sí misma; a su vez, lo característico de la naturaleza irracional es tender al fin como impulsada o dirigida por otro, bien sea a un fin de algún modo conocido, como los simples animales, bien sea a un fin del todo desconocido, como los seres privados de conocimiento"

c) Junto a lo anterior, las acciones libres no son simplemente algo puntual o aislado, sino que en el hombre configuran un cambio, dejan una huella, causan una modalización de su ser, una segunda naturaleza que le hace más justo, leal, sincero... Estamos ante la dimensión autorreferencial de la acción humana, la cual conduce a la adquisición de cualidades éticas que como sabemos facilitan, inclinan y hasta generan sentimientos positivos para repetir la misma acción. De esta manera, el hombre puede crecer en su bondad ética y en consecuencia ir alcanzando una mayor plenitud de su ser personal.

d) Pero no sólo el hombre actúa de un modo práctico sino también técnico. Con su trabajo configura su entorno, lo modifica y lo transforma. Esta actividad transitiva no sólo es una acción sujeta a parámetros físicos, no sólo

\footnotetext{
${ }^{7}$ De la dignidad del hombre. Carta a Hermolao Barbaro y Del ente y el uno (traducción de Luis Martínez Gómez), Editora Nacional, Madrid 1984. En otra traducción se lee: "con el fin de que tú, como árbitro y soberano artífice de ti mismo, te informases y plasmases en la obra que prefirieses." Revista Digital Universitaria. UNAM. 2010. 1 de noviembre 2010, Volumen 11 Número 11.

${ }^{8}$ Tomas de Aquino, Summa Teologica I-II Qu.1 ar. 2.
} 
es un hacer como el ave que construye un nido, es una tarea en la que se hace más hombre, hace más humano el mundo y a los otros hombres. Es decir, aunque el hombre haga tareas que pueden ser suplantadas por máquinas y hasta ser mejor realizadas por ellas éstas tienen también un carácter libre y son ejecutadas bajo una finalidad última de carácter ético.

e) De esta forma nos aproximamos a una de las características más singulares del querer humano. No solo con el querer el hombre pretende crecer en su ser a nivel físico, psíquico o ético, sino que su querer más intenso, su enamoramiento más profundo, tiene relación con los demás hombres. Así podemos observar que en la vida humana se da un tipo de querer especial que calificamos de benevolente o de amistad. Este tipo de amor definido en términos griegos como "Ágape", quiere unirse al otro algo que es efecto de todo tipo de amor- pero no apropiándose del otro, sino dándose al otro, buscando su bien y haciéndolo lo más efectivo posible. Se trata de un querer que intenta afirmar en el ser al otro, que no busca aprovecharse de él. Estamos ante un querer gratuito, incondicional, un don o regalo al otro. Evidentemente, al mismo tiempo que somos capaces de este querer estamos muy inclinados a ser objetos del mismo. Es más, recibir el don reclama en nosotros la reciprocidad de él, con lo que al final aspiramos a la comunión y a trascender nuestro ser en un nosotros superior. De esta forma, los seres humanos constitutivamente incompletos y que no se bastan a sí mismos, alcanzan su mayor plenitud a través de las relaciones interpersonales, las cuales generan una comunión intersubjetiva y remiten nuestro yo a un tú. Un amor que lleva a hacerse semejante al otro, que lleva a pensar y desear en común, que genera desde el recíproco don de sí una historia, una tarea que crece con el paso del tiempo y desearía perdurar para siempre. Un amor "que nunca está concluido y completado que se transforma en la vida, que madura y precisamente por ello permanece fiel a sí mismo, idem velle, idem nolle, querer lo mismo y rechazar lo mismo que el otro." 9

${ }^{9}$ Benedicto XVI. Deus Caritas Est. Madrid, Editorial Palabra, 2006, p. 38. 


\section{Consideraciones finales}

Termino estas reflexiones sobre la singularidad humana. Por un lado me gustaría indicar lo oportunas que son las ideas recogidas en un libro de reciente publicación ${ }^{10}$ para hacer ver la novedad que supone el ser humano y su diferencia con los animales y las máquinas basadas en su especial capacidad de conocimiento. Pero junto a esto no podemos ni debemos olvidar su capacidad volitiva también única. Así en el capítulo 6, del libro indicado con anterioridad ésta es indicada con el término "autodestinación" y en varios momentos se hace hincapié en su importancia ${ }^{11}$. Así pues, considero que no hay que separarlas para tener una visión más íntegra y real de lo especial que es el ser humano. Es más, como bien han puesto de manifiesto diversos autores, ambas capacidades cuando son estudiadas de modo conjunto muestran entre sí una mutua interioridad, en la cual el conocer y el amar pueden intercambiarse su nivel más profundo, en cuanto que todo conocimiento verdadero conduce al amor auténtico y éste nos conduce al verdadero conocimiento. Tal hecho, a mí entender, muestra que a un nivel esencial existe

\footnotetext{
${ }^{10}$ Francisco Rodríguez Valls, Orígenes del hombre. La singularidad del ser humano. Madrid. Editorial Biblioteca Nueva, 2017.

${ }^{11}$ Capitulo 6: Orígenes de la voluntad humana. Una discusión sobre la libertad. Cyborgs, transhumanismo y sociedades virtuales. Valgan también estas frases extraídas del epilogo del libro titulado ¿Qué quiere decirse con la expresión «dignidad» humana?: "Como hemos visto, la forma de saber propia de la persona tiene que ver con la transformación técnica, la determinación moral y la capacidad de fijar objetividades y transmitirlas abstractamente a través del lenguaje. Se caracteriza por una forma peculiar de conciencia. Pero no es una conciencia abstracta sino una conciencia incardinada en un proceso de realización de la que ella misma debería ser artífice. La conciencia humana no es una conciencia «pura» sino encarnada en un proceso de realización existencial que supone un determinado tipo de voluntad. La cuestión es que la subjetividad se estructura de una forma u otra quiera el individuo o no quiera: la realiza o, en todo caso, es realizada, aunque sea por un concreto paso del tiempo sobre ella. Y es que en los procesos de maduración la falta de influencia de la voluntad también supone una constitución de la subjetividad. Conciencia y voluntad que implican la autodestinación son notas constitutivas de lo humano."
} 
una unidad entre el conocimiento y el amor en cuanto emanan de una realidad superior y singular como es el ser humano ${ }^{12}$.

¿Es esto posible en los organismos tecnológicos? ¿Serán capaces de hacerse entre ellos un don sincero de sî́? ¿Podrán realizar actos que conlleven fidelidad al amor? O, ¿̇erán capaces de generar un querer libre e incondicional por los demás? ¿Pueden llegar a tener una voluntad libre, o como máximo, sus elecciones serán el fruto de algoritmos que imitan al hombre? ¿Serán seres responsables de sus decisiones? ¿Mostrarán un impulso de mejora ética que conlleve un crecimiento en sus cualidades éticas? ¿Tendrán verdaderamente esas cualidades? Finalmente, ¿buscarán la felicidad en sus vidas?

\title{
Bibliografia empleada
}

Aquino, T. de Summa Teologica I-II Qu.1 ar.2., Madrid, BAC, 1989.

Benedicto XVI. Deus Caritas Est, Madrid, Editorial Palabra, 2006.

Cortina Ramos, A. Transhumanismo y singularidad tecnologica: superinteligencia, superlongevidad y superbienestar. [http://www.fragmenta.cat/ponencia-de-albertcortina_420424.pdf].

Millán Puelles, A. Fundamentos de Filosofía. Madrid, Ediciones Rialp, 7 edición, 1970.

Pico della Mirandola, G. De la dignidad del hombre. Carta a Hermolao Barbaro y Del ente y el uno (traducción de Luis Martínez Gómez), Madrid, Editora Nacional, 1984.

Ratzinger, J. Introducción al cristianismo, Salamanca, Sígueme, 2001.

Rodríguez Valls, F. Orígenes del hombre. La singularidad del ser humano. Madrid. Editorial Biblioteca Nueva, 2017.

\author{
Luis Miguel Pastor \\ bioetica@um.es
}

\footnotetext{
${ }^{12}$ Así lo expresa Joseph Ratzinger desde un punto de vista teológico "El Dios de la fe es, en cuanto pensar, amor. La idea de que el amor es divino domina toda su concepción. El Logos de todo el mundo, la idea original de la verdad y el amor; allí donde se realiza no hay dos realidades yuxtapuestas o contrarias, sino una, el único Absoluto.” Joseph Ratzinger, Introducción al cristianismo, Salamanca, Sígueme, 2001, pp. 125-126.
} 